TAO, Vol. 16, No. 2, 419-434, June 2005

\title{
A Tendency of Cloud Ratio Associated with the Development of Tropical Water and Ice Clouds
}

\author{
Chung-Hsiung Sui ${ }^{1, *}$ and Xiaofan $\mathrm{Li}^{2}$
}

(Manuscript received 12 May 2004, in final form 24 March 2005)

\begin{abstract}
The ratio of column-integrated cloud content between ice and liquid phases $(C R)$ is a good indicator of cloud dynamics (e.g., convective or stratiform) and radiative properties. Clouds are more stratiform when the $C R$ is larger and more convective for smaller $C R$ values. In this study, a tendency equation of the cloud ratio is derived. The tendency of the cloud ratio $(\partial C R / \partial t)$ is determined by six major cloud microphysical processes: vapor condensation and deposition as cloud sources, rainfall and evaporation of rain as the sinks of water clouds, and melting of graupel and accretion of cloud water by precipitation ice as the major conversion processes between water and ice clouds. Apparently, $\partial C R / \partial t$ is related to water cycling processes among vapor and different categories of clouds, and links the amount of water vapor and clouds with temperature through latent heating.

An analysis of the tendency of the cloud ratio is carried out using hourly zonal-mean data based on a $2 \mathrm{D}$ cloud-resolving simulation with the imposed forcing from the Tropical Ocean Global Atmosphere Coupled OceanAtmosphere Response Experiment. During the genesis and decay stages of clouds (a zonal-mean surface rain rate of smaller than $0.3 \mathrm{~mm} \mathrm{~h}^{-1}$ ), the tendency of the cloud ratio is mainly controlled by the processes related to the vapor condensation and deposition. During the mature stage of clouds (a zonal-mean surface rain rate of larger than $0.3 \mathrm{~mm} \mathrm{~h}^{-1}$ ), the tendency of the cloud ratio is determined by conversion between water and ice clouds through melting of graupel and accretion of cloud water by precipitation ice.
\end{abstract}

${ }^{1}$ Institute of Hydrological Sciences, National Central University, Chung-Li, Taiwan, ROC

2 Joint Center for Satellite Data Assimilation and NOAA/NESDIS/Office of Research and Applications Camp Springs, Maryland, USA

* Corresponding author address: Prof. Chung-Hsiung Sui, Institute of Hydrological Sciences, National Central University, Chung-Li, Taiwan, ROC; E-mail: sui@cc.ncu.edu.tw 
(Key words: Stratiform-Convective Cloud ratio, Cloud microphysics)

\section{INTRODUCTION}

Warm clouds and cold clouds are formed through very different cloud microphysical processes (e.g., Houze 1977). In developing convective cloud regions, precipitation particles grow mostly by collecting cloud water, and the larger raindrops fall out. In regions of decaying convection vertical air motions are generally weaker, and precipitation particles grow mostly by vapor diffusion. These regions are normally referred to as stratiform which are mostly ice clouds. Stratiform clouds typically occur adjacent to regions of developing convective showers. Because of the different dominant cloud microphysical processes involved in ice, and water cloud formations, respective particle size distributions and optical properties of ice, and water clouds are distinctly different, and are intimately linked to the convective and stratiform cloud regions.

Many previous studies have focused on convective/stratiform cloud partitioning based on amplitude and spatial variations of radar reflectivity or the surface rainfall rate, e.g., Churchill and Houze (1984), Caniaux et al. (1994), Steiner et al. (1995), and others. Based on similar criteria, Tao and Simpson (1989), Tao et al. (2000), Sui et al. (1994), Xu (1995), and Lang et al. (2003) developed partition methods that include additional information like cloud content, vertical motion, and the fall speed of precipitation particles. Distinguishing convective and stratiform cloud regions in these studies provide useful insights into studying cloud dynamics and quantitative rainfall estimates. However, it is difficult to quantitatively study cloud microphysical processes in the development of convective/stratiform clouds and precipitations since the mathematical relationship between these microphysical processes linking convective/stratiform clouds cannot be established based on previous cloud partitioning methods.

In this study, the ice water path (IWP: vertically-integrated sum of mixing ratios of cloud ice, snow and graupel), and the liquid water path (LWP: vertically-integrated sum of mixing ratios of cloud water and raindrops) are used to define the cloud ratio (CR: the ratio of the IWP to $L W P$ ). Advantages of using $L W P$ and $I W P$ in defining convective and stratiform clouds are twofold. First, radar and satellite measurements are available for retrieving $L W \mathrm{P}$ and $I W P$ (e.g., measurements by passive and active microwave sensors onboard existing satellites like the NASA/Tropical Rainfall Measurement Mission satellite and NOAA/Advanced Microwave Sounding Unit). Second, $L W P$ and $I W P$ are directly linked to cloud microphysics so the processes influencing the cloud ratio can be studied in a more straightforward way.

While convective and stratiform clouds have been traditionally identified at near pixel scales, their ratio in a larger area reveals some important features associated with the corresponding large-scale disturbances. These include the overall strength of convection, heating profile, lightening, rainfall efficiency, etc. Therefore, observing the $L W P, I W P$, and their ratio in different weather systems in different climate regimes provides essential information for studying some aspects of the relevant physical and dynamic processes. For example, the responses of $L W P$ and $I W P$ to surface warming and large-scale circulation in the tropics are the key water cycling processes determining the radiative-convective feedback to natural or an- 
thropogenic climate forcing. This is best demonstrated in the debates on the controversial "thermostat" hypothesis and "adaptive iris" hypothesis proposed by Ramanthan and Collins (1991) and Lindzen et al. (2001), respectively (see Lau et al. 1994, Lin et al. 2004, and references therein). Another example is that warm-season convection in the pre-monsoon period and monsoon period possess different characteristics: the pre-monsoon rain tends to be more convective while the monsoon rain tends to be stratiform. This again is related to the responses of $L W P$ and $I W P$ to different environmental conditions.

With the above motivation for defining $C R$ as a new partition criterion for convectivestratiform clouds, the $L W P, I W P$, and cloud ratio in a cloud model are analyzed in this study to examine the dominant microphysical processes responsible for the development of tropical water and ice clouds. Through this study, we intend to establish a framework for satellite analysis and climate model studies of convective systems in different weather and climate regimes using $L W P, I W P, C R, C R$ tendency, together with other cloud and dynamic variables. Potential uses of the framework include:

* Statistic analysis (like probability distributions) of $L W P, I W P, C R$, and $C R$ tendency in different large-scale disturbances using satellite data.

* Evaluation of simulated $L W P, I W P, C R$, and $C R$ tendency in different models using explicit cloud microphysics schemes against satellite derived quantities.

* Investigations of responses of water vapor and clouds ( $L W P, I W P, C R$, and $C R$ tendency) to climate forcing anomalies.

This study is based on the hourly zonal-mean data from a two-dimensional (2D) cloudresolving simulation. The model and experiment are briefly described in section 2 . In section 3 , the tendency equation of the cloud ratio is derived based on the prognostic equations of cloud hydrometeors in the $2 \mathrm{D}$ cloud-resolving model. The dominant cloud microphysical processes responsible for the development of convective and stratiform clouds are identified through an analysis of the tendency equation of the cloud ratio based on the hourly zonal-mean data. The summary is given in section 4 .

\section{MODEL AND EXPERIMENT}

The cloud resolving model was originally developed by Soong and Ogura (1980), Soong and Tao (1980), and Tao and Simpson (1993). The 2-D version of the model used by Sui et al. $(1994,1998)$ and further modified by Li et al. (1999) is used in this study. The model predicts potential temperature, specific humidity, zonal and vertical wind, and mixing ratios of five cloud hydrometeors using the governing equations with an anelastic approximation. The model is imposed with the zonally uniform vertical velocity as the main external forcing. The details of the model including cloud microphysics parameterization schemes are referred to $\mathrm{Li}$ et al. $(1999,2002)$. The experiment analyzed in this study is conducted with the model forced by the zonally uniform vertical velocity, zonal wind, and thermal and moisture advections, which are derived by Professor Minghua Zhang and his research group at the State University of New York at Stony Brook, based on the 6-hourly TOGA COARE observations within the Intensive Flux Array (IFA) region (Zhang, personal communication). The calculations are based on the 
constrained variational method on column-integrated budgets of mass, heat, moisture and momentum proposed by Zhang and Lin (1997). Hourly sea surface temperature at the Improved Meteorological (IMET) surface mooring buoy $\left(1.75^{\circ} \mathrm{S}, 156^{\circ} \mathrm{E}\right)$ (Weller and Anderson 1996) is also imposed in the model. The model is integrated from 0400 LST 19 December 1992 to 0400 LST 9 January 1993 (21 days total). Figure 1 shows the time evolution of vertical distribution of the large-scale atmospheric vertical velocity, zonal wind, and the time series of the sea surface temperature (SST) during the 21-day period. In this model setup, the horizontal boundary is periodic. The horizontal domain is $768 \mathrm{~km}$ with a horizontal grid resolution of $1.5 \mathrm{~km}$. The vertical grid resolution ranges from about $200 \mathrm{~m}$ near the surface to about $1 \mathrm{~km}$ near $100 \mathrm{hPa}$. The time step is 12 seconds. Hourly outputs of zonal-mean variables are analyzed in the following discussions.

\section{RESULTS}

Figure 2 displays horizontal-vertical cross sections of the sum of the mixing ratios of cloud hydrometeors $\left(q_{c}+q_{r}+q_{i}+q_{s}+q_{g}\right)$, and vertical profiles of zonal-mean mixing ratios of cloud hydrometeors and vertical velocity at 0800 LST 20, 0000 LST 21, and 0600 LST 24 December 1992, respectively. The zonal-mean $C R$ is 0.2 when several cloud clusters extends

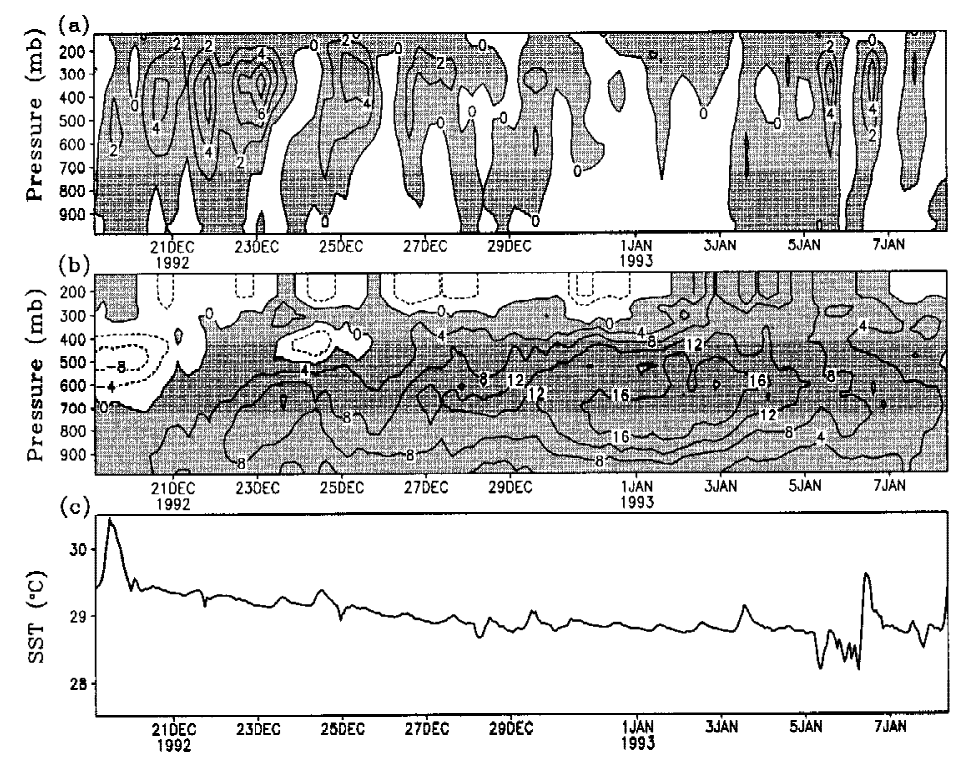

Fig. 1. Temporal and vertical distribution of vertical velocity (a), zonal wind (b), and the time series of sea surface temperature (c) taken from TOGA COARE for 21-day period. Upward motion in (a) and westerly wind in (b) are shaded. Units of vertical velocity, zonal wind, and sea surface temperature are $\mathrm{cm} \mathrm{s}^{-1}, \mathrm{~m} \mathrm{~s}^{-1}$, and ${ }^{\circ} \mathrm{C}$, respectively. 
to $400 \mathrm{mb}$ only and the water clouds dominate at 0800 LST 20 December 1992 (Fig. 2a), representing the development of convective clouds. The vertical velocities in upper and lowertroposphere have similar magnitudes. When clouds extends to $100 \mathrm{mb}$ at $0000 \mathrm{LST} 21 \mathrm{De}-$ cember 1992 (Fig. 2b) and the zonal-mean $C R=0.8$, both ice and water clouds develop. There exists strong upward motion above $600 \mathrm{mb}$ which supports ice clouds. The zonal-mean $C R$ is 2.8 at 0600 LST 24 December 1992 when anvil ice clouds exist and the mixing ratios of ice clouds are larger than those of water clouds (Fig. 2c), denoting the development of stratiform clouds. A strong mean upward motion occurs in the upper-troposphere whereas a downward
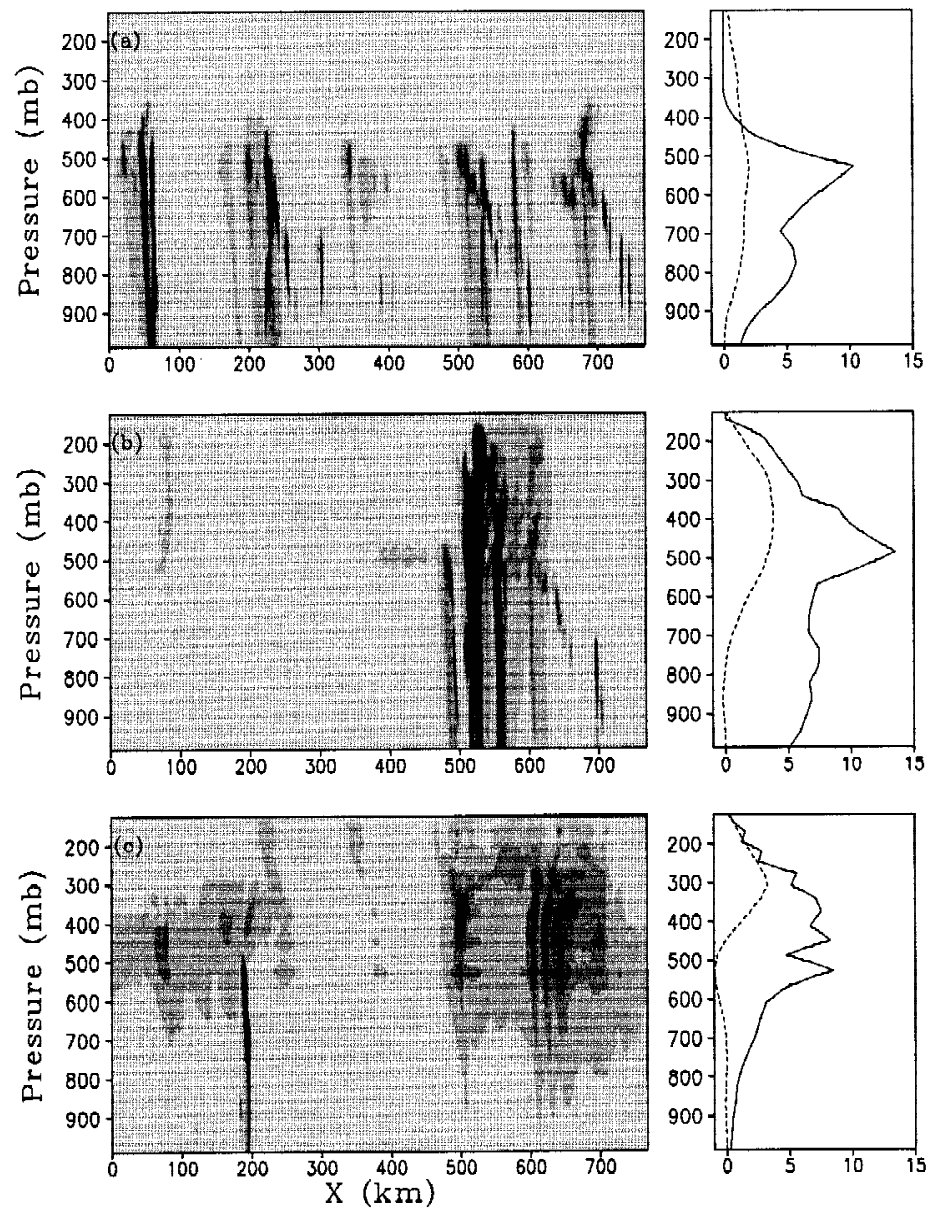

Fig. 2. Horizontal and vertical distributions of mixing ratio of clouds (left panels) and vertical profiles of zonally-averaged mixing ratio of clouds (solid) and vertical velocity (dashed) (right panels) at (a) 0800 LST 20, (b) 0000 LST 21, and (c) 0600 LST 24 December 1992. Units are $10^{-2} \mathrm{~g} \mathrm{~kg}^{-1}$ for mixing ratio of clouds and $\mathrm{cm} \mathrm{s}^{-1}$ for vertical velocity, respectively. 
motion appears in the lower-troposphere.

Since the vertical profiles of vertical velocity strongly impact the vertical profiles of clouds, the layer-mean vertical velocities in upper $\left(\mathrm{w}_{\mathrm{u}}\right)$ and lower $\left(\mathrm{w}_{1}\right)$ troposphere are calculated above $530 \mathrm{mb}$ (about $0^{\circ} \mathrm{C}$ ) and below. Note that the vertical velocity used to calculate the layer-mean here is identical to the imposed zonally-uniform vertical velocity. The fractional covers for stratiform (fcs) and convective (fcc) clouds are also calculated based on Sui et al. (1994). The linear correlation coefficients between the IWP and $\mathrm{w}_{\mathrm{u}}$ and between the $I W P$ and fcs are 0.7 and 0.6, respectively, whereas the linear correlation coefficients between the $L W P$ and $\mathrm{w}_{1}$ and between the $L W P$ and fcc are 0.5 and 0.4 , respectively, which are above $99 \%$ confidence level. This indicates that the large upward motion in upper (lower) troposphere causes the large $I W P(L W P)$ that includes the large fractional cover for stratiform (convective) clouds. Figure 3 shows $C R$ versus $\mathrm{w}_{\mathrm{u}}, \mathrm{w}_{1}$, fcs, and fcc. When $C R<0.4, \mathrm{w}_{1}$ is always positive supporting the strong development of water clouds whereas $\mathrm{w}_{\mathrm{u}}$ could be positive or negative showing weak ice clouds. When $C R>0.4, \mathrm{w}_{\mathrm{u}}$ and fcs are larger than $\mathrm{w}_{\mathrm{l}}$ and fcc, respectively.

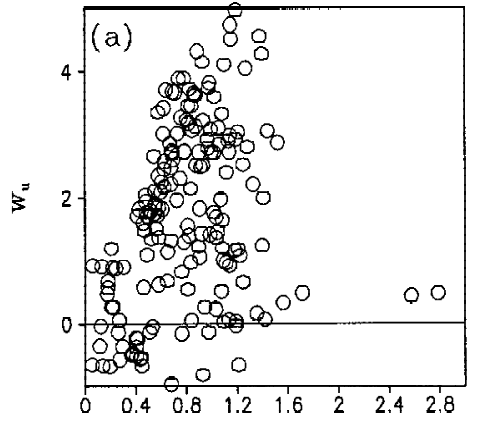

$\mathrm{CR}$

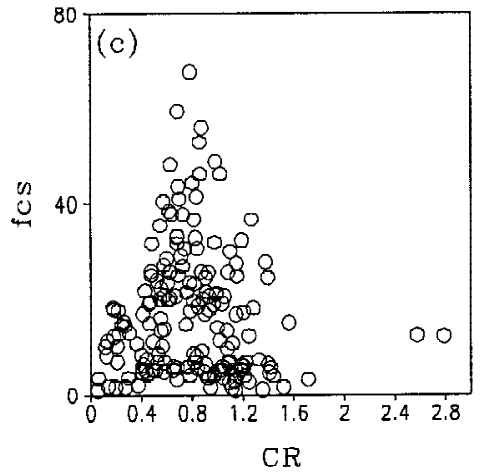

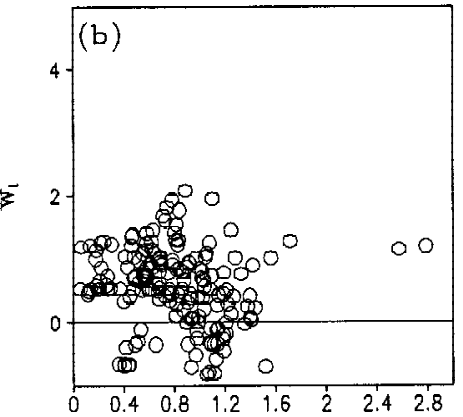

$\mathrm{CR}$

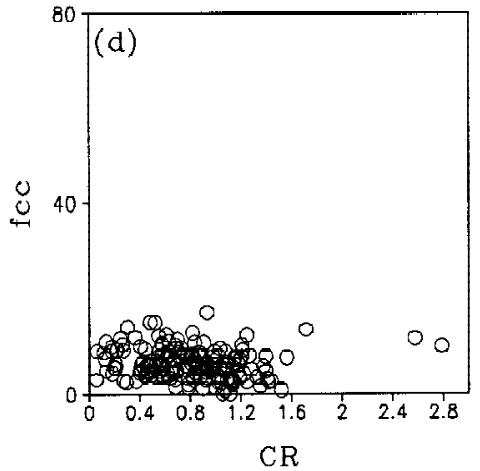

Fig. 3. $C R$ versus layer-mean vertical velocity in upper troposphere $\left(\mathrm{w}_{\mathrm{u}}\right)$ in (a), layer-mean vertical velocity in lower troposphere $\left(\mathrm{w}_{1}\right)$ in $(\mathrm{b})$, fractional cover for stratiform clouds (fcs) in (c), and fractional cover for convective clouds (fcc) in (d). Units are $\mathrm{cm} \mathrm{s}^{-1}$ for $\mathrm{w}_{\mathrm{u}}$ and $\mathrm{w}_{1}$, and $\%$ for fcs and fcc, respectively. 
As $C R$ increases, the upper-tropospheric upward motion becomes stronger and the fractional cover for stratiform clouds becomes larger. The above result indicates that positive layermean (large-scale) vertical velocity is important in triggering convection within which smallerscale updrafts subsequently drive the microphysics of convective clouds.

The results shown in Figs. 2, 3 indicate that the variations of the domain-mean $C R$ directly reflect the variations of convective and stratiform clouds in the domain. Clouds are more stratiform when zonal-mean $C R$ increases whereas clouds tend to be more convective when zonal-mean $C R$ decreases. To further quantify the above observations, we derive a tendency equation of zonal-mean $C R$ next.

The prognostic equations of the mixing ratio of cloud hydrometeors in the $2 \mathrm{D}$ cloud resolving model can be expressed as:

$$
\begin{aligned}
& \frac{\partial q_{c}}{\partial t}=-\frac{\partial\left(u q_{c}\right)}{\partial x}-\frac{1}{\bar{\rho}} \frac{\partial\left(\bar{\rho} w q_{c}\right)}{\partial z}-P_{S A C W}-P_{R A U T}-P_{R A C W}-P_{S F W}\left(T<T_{0}\right)-P_{G A C W}+P_{C N D} \\
& -P_{I H O M}\left(T<T_{00}\right)+P_{I M L T}\left(T>T_{0}\right)-P_{I D W}\left(T_{00}<T<T_{0}\right), \\
& \frac{\partial q_{r}}{\partial t}=-\frac{\partial\left(u q_{r}\right)}{\partial x}-\frac{1}{\rho} \frac{\partial}{\partial z} \bar{\rho}\left(w-w_{T r}\right) q_{r}+P_{S A C W}\left(T>T_{0}\right)+P_{R A U T}+P_{R A C W}+P_{G A C W}\left(T>T_{0}\right) \\
& -P_{R E V P}+P_{R A C S}\left(T>T_{0}\right)-P_{I A C R}\left(T<T_{0}\right)-P_{G A C R}\left(T<T_{0}\right)-P_{S A C R}\left(T<T_{0}\right)-P_{G F R}\left(T<T_{0}\right) \\
& +P_{S M L T}\left(T>T_{0}\right)+P_{G M L T}\left(T>T_{0}\right), \\
& \frac{\partial q_{i}}{\partial t}=-\frac{\partial\left(u q_{i}\right)}{\partial x}-\frac{1}{\bar{\rho}} \frac{\partial\left(\bar{\rho} w q_{i}\right)}{\partial z}-P_{S A U T}\left(T<T_{0}\right)-P_{S A C I}\left(T<T_{0}\right)-P_{R A C I}\left(T<T_{0}\right) \\
& -P_{S F I}\left(T<T_{0}\right)-P_{G A C I}\left(T<T_{0}\right)+P_{I H O M}\left(T<T_{00}\right)-P_{I M L T}\left(T>T_{0}\right)+P_{D E P} \\
& +P_{I D W}\left(T_{00}<T<T_{0}\right), \\
& \frac{\partial q_{s}}{\partial t}=-\frac{\partial\left(u q_{s}\right)}{\partial x}-\frac{1}{\bar{\rho}} \frac{\partial}{\partial z} \bar{\rho}\left(w-w_{T S}\right) q_{S}+P_{S A U T}\left(T<T_{0}\right)+P_{S A C I}\left(T<T_{0}\right)+\delta_{4} P_{S A C C W}\left(T<T_{0}\right) \\
& +P_{S F W}\left(T<T_{0}\right)+P_{S F I}\left(T<T_{0}\right)+\delta_{3} P_{R A C I}\left(T<T_{0}\right)-P_{R A C S}\left(T>T_{0}\right)-P_{G A C S}-P_{S M L T}\left(T>T_{0}\right) \\
& -\left(1-\delta_{2}\right) P_{R A C S}\left(T<T_{0}\right)+\delta_{2} P_{S A C R}\left(T<T_{0}\right)+\left(1-\delta_{1}\right) P_{S D E P}\left(T<T_{0}\right)-P_{M L T S}\left(T>T_{0}\right) \\
& +\delta_{3} P_{I A C R}\left(T<T_{0}\right)-\left(1-\delta_{4}\right) P_{W A C S}\left(T<T_{0}\right), \\
& \frac{\partial q_{g}}{\partial t}=-\frac{\partial\left(u q_{g}\right)}{\partial x}-\frac{1}{\bar{\rho}} \frac{\partial}{\partial z} \bar{\rho}\left(w-w_{T g}\right) q_{g}+\left(1-\delta_{3}\right) P_{R A C I}\left(T<T_{0}\right)+P_{G A C I}\left(T<T_{0}\right) \\
& +P_{G A C W}\left(T<T_{0}\right)+P_{G A C S}+\left(1-\delta_{4}\right) P_{S A C W}\left(T<T_{0}\right)+\left(1-\delta_{3}\right) P_{I A C R}\left(T<T_{0}\right)+P_{G A C R}\left(T<T_{0}\right) \\
& +P_{G F R}\left(T<T_{0}\right)+\left(1-\delta_{2}\right) P_{R A C S}\left(T<T_{0}\right)+\left(1-\delta_{4}\right) P_{W A C S}\left(T<T_{0}\right)-P_{G M L T}\left(T>T_{0}\right) \\
& +\left(1-\delta_{1}\right) P_{G D E P}\left(T<T_{0}\right)-P_{M L T G}\left(T>T_{0}\right)+\left(1-\delta_{2}\right) P_{S A C R}\left(T<T_{0}\right), \\
& \\
& +(4)
\end{aligned}
$$


where $q_{c}, q_{r}, q_{i}, q_{s}, q_{g}$ are the mixing ratios of cloud water (small cloud droplets), raindrops, cloud ice (small ice crystals), snow (density $0.1 \mathrm{~g} \mathrm{~cm}^{-3}$ ), and graupel (density $0.4 \mathrm{~g} \mathrm{~cm}^{-3}$ ), respectively. The microphysical processes in the terms of the right-hand side of (1) - (5) and corresponding schemes are listed in Table 1, and definitions and values of the other quantities can be found in Li et al. $(1999,2002)$.

To derive the tendency equation of the $C R$, we first add (1) - (2) and (3) - (5) respectively and vertically integrate the resulting equations to yield:

$$
\begin{aligned}
& \frac{\partial L W P}{\partial t}=C O N V_{L W P}-P_{r}+\left[P_{C N D}\right]+C(I W P, L W P)-\left[P_{R E V P}\right], \\
& \frac{\partial I W P}{\partial t}=C O N V_{I W P}+\left[P_{D E P}\right]+\left[\left(1-\delta_{1}\right) P_{S D E P}\right]+\left[\left(1-\delta_{1}\right) P_{G D E P}\right]-C(I W P, L W P) \\
& -P_{M L T S}\left(T>T_{0}\right)-P_{M L T G}\left(T>T_{0}\right)-P_{s}-P_{g},
\end{aligned}
$$

where

$$
\begin{aligned}
& C O N V_{L W P}=-\left[\frac{\partial}{\partial x} u\left(q_{c}+q_{r}\right)\right], \\
& C O N V_{I W P}=-\left[\frac{\partial}{\partial x} u\left(q_{i}+q_{s}+q_{g}\right)\right], \\
& P_{r}=\left.\bar{\rho} w_{T r} q_{r}\right|_{z=0}, \\
& P_{s}=\left.\bar{\rho} w_{T s} q_{s}\right|_{z=0},
\end{aligned}
$$

$C(I W P, L W P)=-\left[P_{S A C W}\left(T<T_{0}\right)\right]-\left[P_{S F W}\left(T<T_{0}\right)\right]-\left[P_{G A C W}\left(T<T_{0}\right)\right]-\left[P_{I H O M}\left(T<T_{00}\right)\right]$

$+\left[P_{I M L T}\left(T>T_{0}\right)\right]-\left[P_{I D W}\left(T_{00}<T<T_{0}\right)\right]+\left[P_{R A C S}\left(T<T_{0}\right)\right]-\left[P_{I A C R}\left(T<T_{0}\right)\right]$

$-\left[P_{G A C R}\left(T<T_{0}\right)\right]-\left[P_{S A C R}\left(T<T_{0}\right)\right]-\left[P_{G F R}\left(T<T_{0}\right)\right]+\left[P_{S M L T}\left(T>T_{0}\right)\right]+\left[P_{G M L T}\left(T>T_{0}\right)\right]$.

Here, $[()]=\int_{z_{b}}^{z_{t}} \bar{\rho}() d z, z_{t}$ and $z_{b}$ are the heights of the top and bottom of the model atmosphere respectively.

In the tropical deep convective regime, $C(I W P, L W P)$ is simplified as $\left[P_{G M L T}\right]-\left[P_{S A C W}\right]-\left[P_{G A C W}\right]$ 
(Li et al. 2002). Precipitation due to snow and graupel $\left(P_{s}\right.$ and $\left.P_{g}\right)$ are negligible, and $P_{r}$ accounts for surface rain rate $\left(P_{s f c}\right) \cdot\left[P_{D E P}\right]+\left[P_{S D E P}\right]+\left[P_{G D E P}\right]=\left[\sum P_{D E P}\right]$. Therefore, (6) - (7) can be simplified as:

$$
\begin{aligned}
& \frac{\partial L W P}{\partial t}=C O N V_{L W P}-P_{s f C}+\left[P_{C N D}\right]+C(I W P, L W P)-\left[P_{R E V P}\right], \\
& \frac{\partial I W P}{\partial t}=C O N V_{I W P}+\left[\sum P_{D E P}\right]-C(I W P, L W P) .
\end{aligned}
$$

Take zonal mean on (9), (9) becomes

$$
\begin{aligned}
& \frac{\partial L W P}{\partial t}=-P_{s f c}+\left[P_{C N D}\right]+C(I W P, L W P)-\left[P_{R E V P}\right], \\
& \frac{\partial I W P}{\partial t}=\left[\sum P_{D E P}\right]-C(I W P, L W P)
\end{aligned}
$$

Note that all quantities in (10) are zonally averaged. Thus, the zonal mean of (8a) and (8b) are excluded in (10).

Taking time derivative of zonal-mean $C R$ and using (10), the tendency equation of zonalmean $C R$ can be expressed by:

$$
\frac{1}{C R} \frac{\partial C R}{\partial t}=C(L W P, I W P)\left(\frac{L W P+I W P}{L W P \times I W P}\right)+\frac{\left[\sum P_{D E P}\right]}{I W P}-\frac{\left[P_{C N D}\right]}{L W P}+\frac{P_{s f C}}{L W P}+\frac{\left[P_{R E V P}\right]}{L W P}
$$

Note that the relation $-C(I W P, L W P)=C(L W P, I W P)$ is used in (11). Eq. (11) can be shown schematically in Fig. 4. Eq. (11) shows that the tendency of the zonal-mean $C R$ is determined by the conversion between $L W P$ and $I W P$ through the melting of graupel and the accretion of cloud water by precipitation ice, vapor condensation and deposition, rainfall, and evaporation of rain. Accretion of cloud water by precipitation ice and vapor deposition enhance the development of ice clouds, and rainfall and evaporation of rain suppress the development of water clouds increasing the cloud ratio whereas melting of graupel and vapor condensation enhance the development of water clouds decreasing the cloud ratio.

Dominant responsible processes for variations of the $C R$ may be different in different development stages of clouds denoted by different rain rates. Thus, an analysis of the $C R$ budgets is carried out here in different stages based on hourly cumulative microphysical budget terms. Two stages are formed by dividing the data in two groups based on a threshold surface rainfall rate. The small and large surface rain rates represent the clouds in the stages of the genesis/decay and development/mature, respectively. Since the time-mean surface rain 
rate during the integration is $0.37 \mathrm{~mm} \mathrm{~h}^{-1}$, we choose $\mathrm{P}_{\text {sfc }}<0.3 \mathrm{~mm} \mathrm{~h}^{-1}$ and $\mathrm{P}_{\text {sfc }}>0.3 \mathrm{~mm} \mathrm{~h}^{-1}$ to define the two groups. We also tested different threshold values of $\mathrm{P}_{\text {sfc }}$ and the results are similar. Figures 5 and 6 show $\ln C R$ tendency versus the contributions from the melting of graupel and accretion of cloud water by precipitation ice, vapor deposition and condensation, and rainfall and evaporation of rain when $\mathrm{P}_{\text {sfc }}<0.3 \mathrm{~mm} \mathrm{~h}^{-1}$ and $\mathrm{P}_{\text {sfc }}>0.3 \mathrm{~mm} \mathrm{~h}^{-1}$, respectively. When $\mathrm{P}_{\text {sfc }}<0.3 \mathrm{~mm} \mathrm{~h}^{-1}$, the linear correlation coefficients and root-mean-square differences between $\ell n C R$ tendency and its components are 0.13 and $2.31 \mathrm{~h}^{-1}$ for $C(L W P, I W P)\left(\frac{L W P+I W P}{L W P \times I W P}\right)$, 0.66 and $1.5 \mathrm{~h}^{-1}$ for $\frac{\left[\sum P_{D E P}\right]}{I W P}-\frac{\left[P_{C N D}\right]}{L W P}$, and 0.14 and $3.33 \mathrm{~h}^{-1}$ for $\frac{P_{s f C}}{L W P}+\frac{\left[P_{R E V P}\right]}{L W P}$, respectively. Thus, the $\ln C R$ tendency is mainly determined by $\frac{\left[\sum P_{D E P}\right]}{I W P}-\frac{\left[P_{C N D}\right]}{L W P}$ (Fig. 5b). The $\ln C R$ tendency increases with increasing $\left(\frac{\left[\sum P_{D E P}\right]}{I W P}-\frac{\left[P_{C N D}\right]}{L W P}\right)$, indicating the vapor condensation and deposition rates associated with the upward motion are responsible for the variations of cloud ratio and the variations of convective and stratiform clouds. Since $\frac{\left[\sum P_{D E P}\right]}{I W P}$ is a constant of 0.8 statistically (not shown), the $\ln C R$ tendency depends largely on $\frac{\left[P_{C N D}\right]}{L W P}$. The $C R$ decreases (increases) and clouds are more convective (stratiform) when $\frac{\left[P_{C N D}\right]}{L W P}$ is larger (smaller)

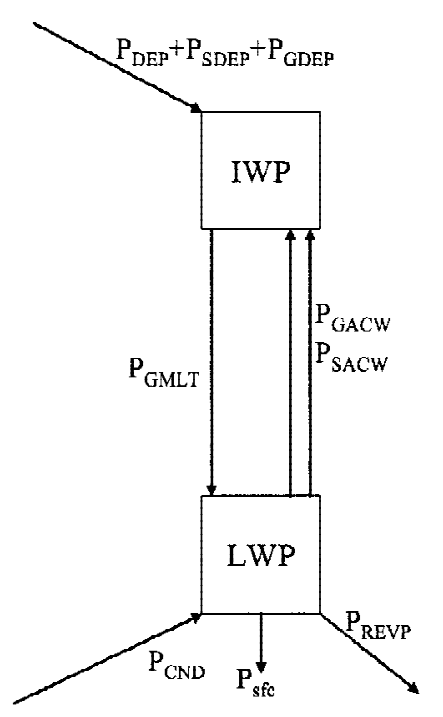

Fig. 4. A schematic diagram for exchange between water (LWP) and ice (IWP) clouds and cloud sources. The description of conversion terms can be found in Table 1. 
than $\frac{\left[\sum P_{D E P}\right]}{I W P}$. When $\mathrm{P}_{\mathrm{sfc}}>0.3 \mathrm{~mm} \mathrm{~h}^{-1}$, the linear correlation coefficients and root-meansquare differences between $\ln C R$ tendency and its components are 0.78 and $1.76 \mathrm{~h}^{-1}$ for $C(L W P, I W P)\left(\frac{L W P+I W P}{L W P \times I W P}\right), 0.01$ and $2.81 \mathrm{~h}^{-1}$ for $\frac{\left[\sum P_{D E P}\right]}{I W P}-\frac{\left[P_{C N D}\right]}{L W P}$, and 0.27 and $3.55 \mathrm{~h}^{-1}$ for $\frac{P_{s f c}}{L W P}+\frac{\left[P_{R E V P}\right]}{L W P}$, respectively. Thus, the $\ln C R$ tendency is mainly contributed by

Table 1. List of microphysical processes and their parameterization schemes in appendix. The schemes are Rutledge and Hobbs (1983, 1984; RH83, RH84), Lin et al. (1983, LFO), Tao et al. (1989, TSM), and Krueger et al. (1995, KFLC).

\begin{tabular}{|c|c|c|}
\hline Notation & Description & Scheme \\
\hline PMLTG & Growth of vapor by evaporation of liquid from graupel surface & RH84 \\
\hline PMLTS & Growth of vapor by evaporation of melting snow & RH83 \\
\hline $\mathrm{P}_{\mathrm{REVP}}$ & Growth of vapor by evaporation of raindrops & RH83 \\
\hline $\mathrm{P}_{\text {IMLT }}$ & Growth of cloud water by melting of cloud ice & RH83 \\
\hline $\mathrm{P}_{\mathrm{CND}}$ & Growth of cloud water by the condensation of supersaturated vapor & TSM \\
\hline $\mathrm{P}_{\text {GMLT }}$ & Growth of raindrops by melting of graupel & RH84 \\
\hline$P_{\text {SMLT }}$ & Growth of raindrops by melting of snow & RH83 \\
\hline $\mathrm{P}_{\mathrm{RACI}}$ & Growth of raindrops by the accretion of cloud ice & RH84 \\
\hline $\mathrm{P}_{\mathrm{RACW}}$ & Growth of raindrops by the collection of cloud water & RH83 \\
\hline$P_{\text {RACS }}$ & Growth of raindrops by the accretion of snow & RH84 \\
\hline$P_{\text {RAUT }}$ & Growth of raindrops by the autoconversion of cloud water & LFO \\
\hline PIDW & Growth of cloud ice by the deposition of cloud water & KFLC \\
\hline $\mathrm{P}_{\mathrm{IACR}}$ & Growth of cloud ice by the accretion of rain & RH84 \\
\hline PIITOM & Growth of cloud ice by the homogeneous freezing of cloud water & \\
\hline $\mathrm{P}_{\mathrm{DEP}}$ & Growth of cloud ice by the deposition of supersaturated vapor & TSM \\
\hline PAUT & Growth of snow by the conversion of cloud ice & RH83 \\
\hline $\mathrm{P}_{\mathrm{SACl}}$ & Growth of snow by the collection of cloud ice & RH83 \\
\hline $\mathrm{P}_{\mathrm{SACW}}$ & Growth of snow by the accretion of cloud water & RH83 \\
\hline $\mathrm{P}_{\mathrm{SFW}}$ & Growth of snow by the deposition of cloud water & KFLC \\
\hline $\mathrm{P}_{\text {SFI }}$ & Depositional growth of snow from cloud ice & KFLC \\
\hline$P_{\text {SACR }}$ & Growth of snow by the accretion of raindrops & LFO \\
\hline$P_{\text {SDEP }}$ & Growth of snow by the deposition of vapor & RH83 \\
\hline $\mathrm{P}_{\mathrm{GACl}}$ & Growth of graupel by the collection of cloud ice & RH84 \\
\hline $\mathrm{P}_{\mathrm{GACR}}$ & Growth of graupel by the accretion of raindrops & RH84 \\
\hline $\mathrm{P}_{\mathrm{GACS}}$ & Growth of graupel by the accretion of snow & RH84 \\
\hline $\mathrm{P}_{\mathrm{GACW}}$ & Growth of graupel by the accretion of cloud water & RH84 \\
\hline$P_{\text {WACS }}$ & Growth of graupel by the riming of snow & RH84 \\
\hline$P_{\text {GDEP }}$ & Growth of graupel by the deposition of vapor & RH84 \\
\hline $\mathrm{P}_{\mathrm{GFR}}$ & Growth of graupel by the freezing of raindrops & LFO \\
\hline
\end{tabular}



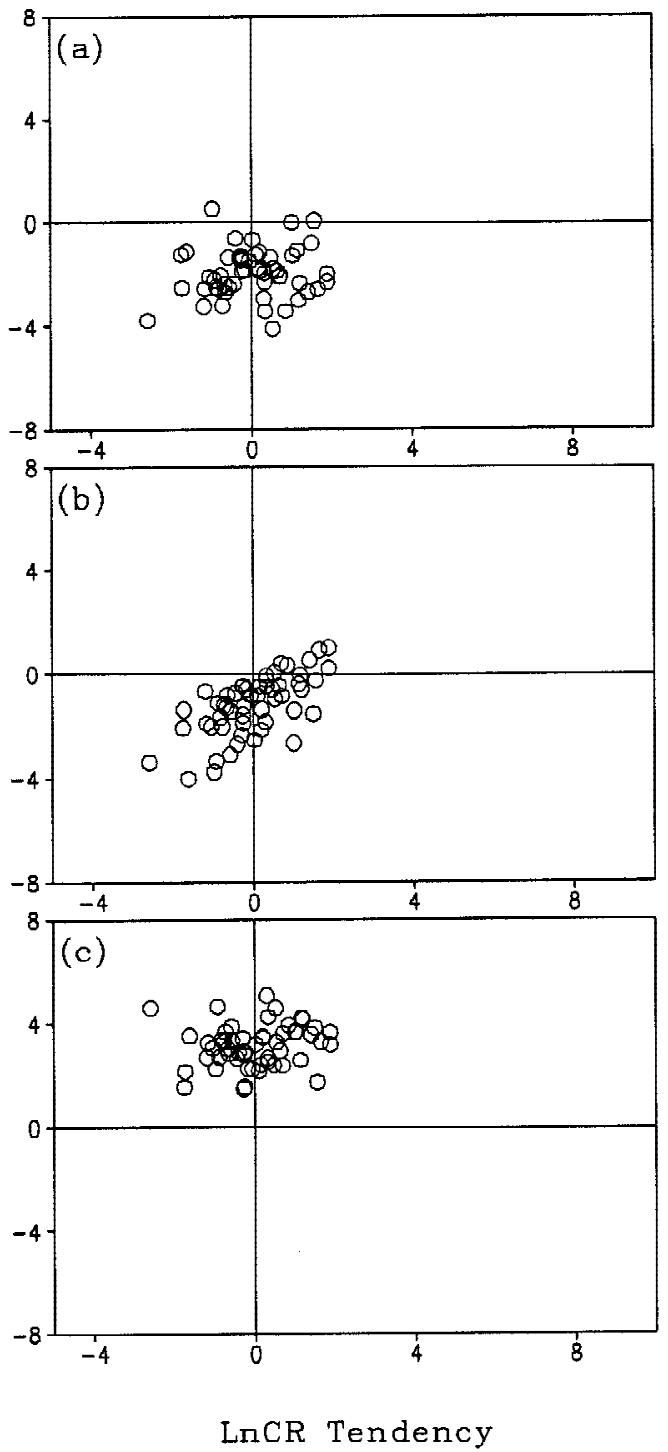

Fig. 5. $\ln C R$ tendency versus the contributions from the melting of graupel and accretion of cloud water by precipitation ice in (a), vapor deposition and condensation in (b), and rainfall and evaporation of rain in (c) using the zonal mean data when the zonal mean surface rain rates are smaller than $0.3 \mathrm{~mm} \mathrm{~h}^{-1}$. Unit is $\mathrm{h}^{-1}$. 
$C(L W P, I W P)\left(\frac{L W P+I W P}{L W P \times I W P}\right)$ (Fig. 6a). The $\ell n C R$ tendency increases with increasing $\left(\left[P_{S A C W}\right]+\left[P_{G A C W}\right]-\left[P_{G M L T}\right]\right)$. The $C R$ decreases (increases) and clouds are more convective (stratiform) when the melting rate of graupel is larger (smaller) than the accretion rate of cloud water by precipitation ice in the mature stages of clouds.
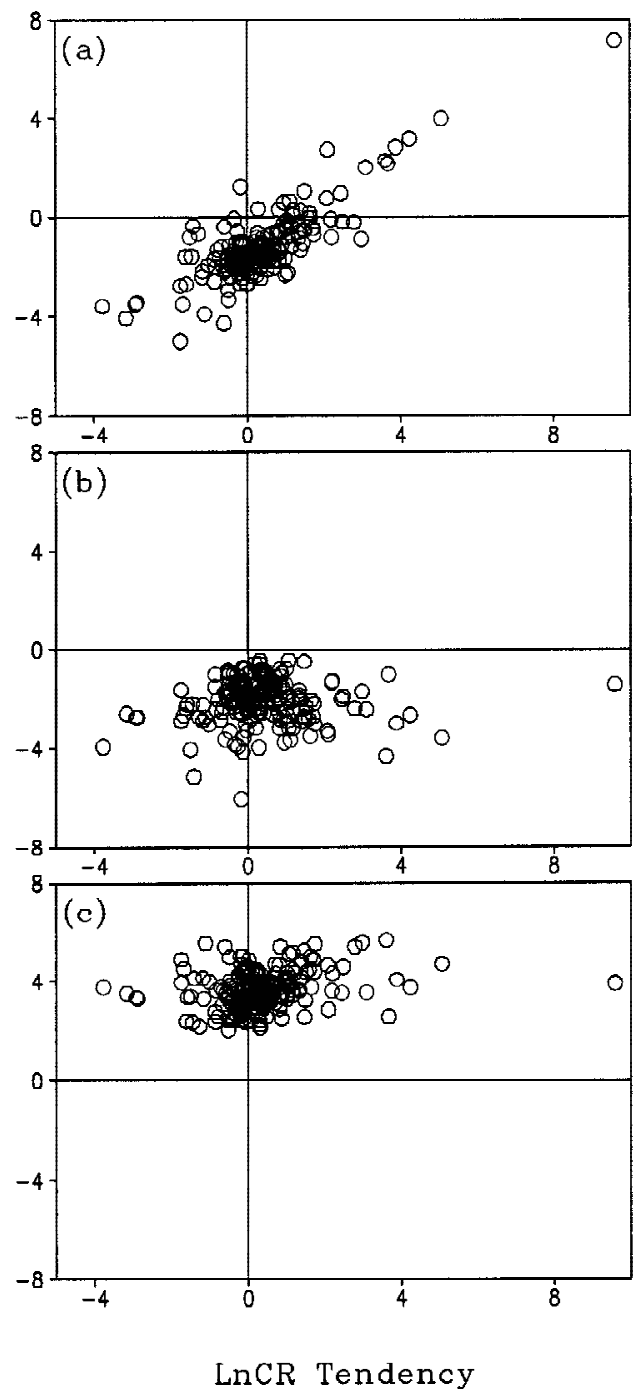

Fig. 6. Same as in Fig. 5 except when the zonal mean surface rain rates are larger than $0.3 \mathrm{~mm} \mathrm{~h}^{-1}$. 


\section{SUMMARY}

A cloud ratio that is defined as the ratio of the ice water path and the liquid water path is introduced in this study to quantitatively measure convective and stratiform clouds, depending on the relative dominance of water/ice clouds. More convective (stratiform) clouds are associated with smaller (larger) cloud ratios which are shown to be related to weaker (stronger) upward motion above the freezing level relative to the vertical velocity below the freezing level. The tendency of the cloud ratio gauges the development of convective/stratiform clouds. Thus, a tendency equation of the cloud ratio is derived based on the prognostic equations of cloud hydrometeors in the cloud resolving model. The analysis of the tendency of the cloud ratio is carried out using hourly zonal-mean data from the $2 \mathrm{D}$ cloud-resolving simulation. The cloud model is integrated with the imposed forcing from the Tropical Ocean Global Atmosphere Coupled Ocean-Atmosphere Response Experiment for the selected 21-day period.

The tendency of the zonal-mean $C R$ is determined by six major cloud microphysical processes: vapor condensation and deposition as cloud sources, rainfall and evaporation of rain as the sinks of water clouds, and melting of graupel and accretion of cloud water by precipitation ice as the major conversion processes between water and ice clouds. The analysis is performed in two groups: one group with a zonal-mean surface rain rate smaller than $0.3 \mathrm{~mm} \mathrm{~h}^{-1}$, and the other group with a zonal-mean surface rain rate larger than $0.3 \mathrm{~mm} \mathrm{~h}^{-1}$. The group with small surface rain rates represents cases during the genesis/decay stage of clouds whereas the group with large surface rain rates denotes cases during the mature stage of clouds. During the genesis and decay stages of clouds, the tendency of the $C R$ is mainly controlled by vapor condensation and deposition processes, indicating the condensation and deposition processes play important roles in determining the formation and decay of clouds. During the mature stages of clouds, the tendency of the $C R$ is determined by conversion between existing water and ice clouds through the melting of graupel and accretion of cloud water by precipitation ice.

The primary microphysical process responsible for growth of convective rainfall is a collection of cloud water by rain particles in the strong updraft cores whereas the primary microphysical process responsible for the growth of stratiform clouds is vapor deposition on ice particles (e.g., Houghton 1968, Houze 1977). In this study, since the liquid water path is the combination of cloud water and raindrops, the collection of cloud water by rain $\left(P_{R A C W}\right)$ is not explicitly expressed in (11). The budget of cloud water shows that a large vapor condensation rate is correlated with a large collection rate of cloud water by rain, indicating the vapor condensation rate may indirectly affect the collection rate by changing the amount of cloud water available for collection (e.g., Li et al. 2002). Thus, our results show that vapor condensation and deposition are the major processes responsible for the growth of convective and stratiform clouds, respectively, in the onset/decay stages of tropical clouds, which are consistent with the existing knowledge. Our results also show that when water and ice clouds develop to a mature stage, the conversion processes between the existing water and ice clouds through the melting of precipitation ice and accretion of cloud water by precipitation ice may play an important role in the development of convective/stratiform clouds while other processes such as vapor condensation and deposition may be secondary factors. The results in the mature stage have not been discussed before and await further studies. Nevertheless, the analysis of the cloud 
ratio demonstrates that derivation of the tendency equation of the cloud ratio leads to the establishment of a microphysical framework, which is a powerful tool for the investigation of development of convective/stratiform clouds.

Acknowledgments Authors thank Prof. M. Zhang at the State University of New York at Stony Brook for TOGA COARE forcing data, Prof. M. J. Yang at the National Central University who reviewed the manuscript and offered valuable comments that improve the scientific content of the current study and two anonymous reviewers for their constructive comments. This research has been supported by NSC 91-2111-M-008-027.

\section{REFERENCES}

Caniaux, G., J. L. Redelsperger, and J. P. Lafore, 1994: A numerical study of the stratiform region of a fast-moving squall line. Part I: General description and water and heat budgets. J. Atmos. Sci., 51, 2046-2074.

Churchill, D. D., and R. A. Houze, Jr., 1984: Development and structure of winter monsoon cloud clusters on 10 December 1978. J. Atmos. Sci., 41, 933-960.

Houghton, H. G., 1968: On precipitation mechanisms and their artificial modification.J. Appl. Meteor., 7, 851-859.

Houze, R. A., Jr., 1977: Stratiform Precipitation in Regions of Convection: A Meteorological Paradox? Bull. Am. Meteor. Soc., 78, 2179-2196.

Krueger, S. K., Q. Fu, K. N. Liou, and H.-N. S. Chin, 1995: Improvement of an ice-phase microphysics parameterization for use in numerical simulations of tropical convection. J. Appl. Meteor., 34, 281-287.

Lang, S., W. K. Tao, J. Simpson, and B. Ferrier 2003: Modeling of convective-stratiform precipitation processes: Sensitivity to partition methods.J. Appl. Meteor., 42, 505-527.

Lau, K. M., C. H. Sui, M.-D. Chou, and W. K. Tao, 1994: Cirrus cloud thermostat effect for tropical sea surface temperature-fact or fiction. Geophys. Res. Lett., 21, 1157-1160.

Li, X., C. H. Sui, K. M. Lau, and M.-D. Chou, 1999: Large-scale forcing and cloud-radiation interaction in the tropical deep convective regime.J. Atmos. Sci., 56, 3028-3042.

Li, X., C. H. Sui, and K. M. Lau, 2002: Dominant cloud microphysical processes in a tropical oceanic convective system: A 2-D cloud resolving modeling study.Mon. Wea. Rev., 130, 2481-2491.

Lin, Y. L., R. D. Farley, and H. D. Orville, 1983: Bulk parameterization of the snow field in a cloud model. J. Climate Appl. Meteor., 22, 1065-1092.

Lin, B., T. Wong, B. A. Wielicki, and Y. Hu, 2004: Examination of the decadal tropical mean ERBS nonscanner radiation data for the Iris hypothesis. J. Climate, 17, 1239-1246.

Lindzen, R. S., M. D. Chou, and A. Hou, 2001: Does the earth have an adaptive infrared Iris? Bull. Am. Meteor. Soc., 82, 417-432.

Ramanthan, V., and W. Collins, 1991: Thermodynamic regulation of ocean warming by cirrus clouds deduced from observations of the 1987 El Niño. Nature, 351, 27-32. 
Rutledge, S. A., and P. V. Hobbs, 1983: The mesoscale and microscale structure and organization of clouds and precipitation in midlatitude cyclones. Part VIII: A model for the "seeder-feeder" process in warm-frontal rainbands. J. Atmos. Sci., 40, 1185-1206.

Rutledge, S. A., and P. V. Hobbs, 1984: The mesoscale and microscale structure and organization of clouds and precipitation in midlatitude cyclones. Part XII: A disgnostic modeling study of precipitation development in narrow cold-frontal rainbands. J. Atmos. Sci., 41, 2949-2972.

Soong, S. T., and Y. Ogura, 1980: Response of tradewind cumuli to large-scale processes. $J$. Atmos. Sci., 37, 2035-2050.

Soong, S. T., and W. K. Tao, 1980: Response of deep tropical cumulus clouds to Mesoscale processes. J. Atmos. Sci., 37, 2016-2034.

Steiner, M., R. A. Houze Jr., and S. E. Yuter, 1995: Climatological characterization of threedimensional storm structure from operational radar and rain gauge data.J. Appl. Meteor., 34, 1978-2007.

Sui, C. H., K. M. Lau, W. K. Tao, and J. Simpson, 1994: The tropical water and energy cycles in a cumulus ensemble model. Part I: Equilibrium climate.J. Atmos. Sci., 51, 711-728.

Sui, C. H., X. Li, and K. M. Lau, 1998: Radiative-convective processes in simulated diurnal variations of tropical oceanic convection. J. Atmos. Sci., 55, 2345-2359.

Tao, W. K., and J. Simpson, 1989: Modeling study of a tropical squall-type convective line.J. Atmos. Sci., 46, 177-202.

Tao, W. K., and J. Simpson, 1993: The Goddard Cumulus Ensemble model. Part I: Model description. Terr. Atmos. Ocean. Sci., 4, 35-72.

Tao, W. K, J. Simpson, and M. McCumber, 1989: An ice-water saturation adjustment.Mon. Wea. Rev., 117, 231-235.

Tao, W. K., S. Lang, J. Simpson, W. S. Olson, D. Johnson, B. Ferrier, C. Kummerow, and R. Adler, 2000: Vertical profiles of latent heat release and their retrieval for TOGA COARE convective systems using a cloud resolving model, SSM/I, and ship-borne radar data. J. Meteor. Soc. Japan, 78, 333-355.

Weller, R. A., and S. P. Anderson, 1996: Surface meteorology and air-sea fluxes in the western equatorial Pacific warm pool during TOGA COARE.J. Climate, 9, 1959-1990.

Xu, K. M., 1995: Partitioning mass, heat, and moisture budgets of explicit simulated cumulus ensembles into convective and stratiform components. J. Atmos. Sci., 52, 1-23.

Zhang, M. H., and J. L. Lin, 1997: Constrained variational analysis of sounding data based on column-integrated budgets of mass, heat, moisture, and momentum: Approach and application to ARM measurements. J. Atmos. Sci., 54, 1503-1524. 